\title{
Characterization and field evaluation of tetrahedral and triangular nucleopolyhedrovirus of Spilosoma obliqua (SpobNPV) strain NBAIR1 against jute hairy caterpillar
}

\author{
G. Sivakumar ${ }^{1 *}$, M. Kannan², V. Ramesh Babu ${ }^{3}$, M. Mohan ${ }^{1}$, Surabhi Kumari ${ }^{1}$, R. Rangeshwaran ${ }^{1}$, T. Venkatesan ${ }^{1}$ and \\ Chandish R. Ballal ${ }^{1}$
}

\begin{abstract}
Jute hairy caterpillar, Spilosoma (=Spilarctia) obliqua (Walker) (Arctiidae: Lepidoptera), is an irregular and polyphagous insect pest that occurs all over India. A severe natural viral epizootic was observed in the field population of S. obliqua in jute. The virus was characterized as Spilosoma obliqua nucleopolyhedrovirus (SpobNPV NBAIR1) based on morphological, biological, and molecular characterization. Under scanning and transmission electron microscopy (SEM and TEM), the occlusion bodies (OBs) of SpobNPV NBAIR1 appeared as both tetrahedral and triangular with the size ranged from 1.04-1.72 $\mu \mathrm{m}$. The results on the bioassay studies revealed that the lowest $\mathrm{LC}_{50}$ value of $2.93 \mathrm{OBs} / \mathrm{mm}^{2}$ by leaf disc bioassay against the second instar S. obliqua showed its high virulence. The identity of SpobNPV was further confirmed by the amplification of polyhedrin gene (NCBI GenBank accession no. MK288145). Eleven species of lepidopteran insects, viz., Spodoptera litura, S. exigua, S. frugiperda, Helicoverpa armigera, Plutella xylostella, Amsacta albistriga, Maruca vitrata, Trichoplusia ni, Pieris brassicae, Agrotis ipsilon, and Bombyx mori, were not susceptible to the infection with SpobNPV NBAIR1. Field experiments on jute crop revealed $68.92,78.59$, and $93.16 \%$ reduction in larval population of S. obliqua at 3, 4, and 7 days post spray of SpobNPV NBAIR1 $\left(1.5 \times 10^{12} \mathrm{OBs} / \mathrm{ha}\right.$ at $\left.2 \mathrm{ml} / \mathrm{l}\right)$, respectively. The present study is a renewed effort in the management of $S$. obliqua by the new strain of SpobNPV NBAIR1.
\end{abstract}

Keywords: Characterization, Spilosoma obliqua, Nucleopolyhedrovirus, SpobNPV, NBAIR1

\section{Background}

Jute hairy caterpillar, Spilosoma (= Spilarctia) obliqua (Walker) (Arctiidae: Lepidoptera), is an important polyphagous insect pest broadly distributed across India (CPC 2004). It damages about 126 plant species including pulses, oilseeds, cereals, vegetables, mulberry, turmeric, and fiber crops (jute, mesta, and ramie) that

\footnotetext{
*Correspondence: sivakumarg.nbaii@gmail.com

'ICAR-National Bureau of Agricultural Insect Resources, Bengaluru 560 024, India

Full list of author information is available at the end of the article
}

causes a high economic loss (Senthil Kumar et al. 2011). Spilosoma obliqua is an important pest of fiber crops in India and epidemic of the occurrence has been documented in jute and sunn hemp during 2011 and 2012 (Satpathy et al. 2014). Despite its larvae being parasitized by natural enemies, they continue to emerge in large numbers and infest the crops sporadically. The insect pest is polyphagous and infests several weeds and cultivated plants; chemical control is not feasible and economical (Gupta and Bhattacharya 2008). Though spraying of insecticides is not a permanent solution, 
farmers solely rely on pesticides for its control. The continuous and indiscriminate uses of synthetic chemical insecticides have led to development of resistance besides environmental hazards. Farmers concern about chemical pesticide residues on food is driving the search for an alternative method of pest control.

Viral bio-control agent has also been recognized as inherently less toxic, eco-friendly than conventional chemical pesticides (Gramkow et al. 2010). Hence, their use as a biological pest control agent has been greatly encouraged with assumed comparative advantage as fastidious host-specific organisms (Gramkow et al. 2010). Biological control agents are often used as an important environment-friendly component in IPM strategy. Lethal and sublethal concentrations of baculoviruses infected larvae are very sluggish in movement with prolonged developmental periods, which facilitates the easier parasitization and predation by natural enemies. This interaction provides high multiplication of natural enemies under field conditions to suppress the pest population (Jehle et al. 2006a; Fan et al. 2008). Hence, the use of baculoviruses in bio-control of insect pests of agricultural importance is gaining momentum as frontiers of environmental biocontrol pathogens (Georgievska et al. 2010; Jeremy et al. 2015). The full potential of these viral biopesticides has to be exploited, the development and identification of more effective strains with enhancing formation of occlusion bodies (OBs) are necessary for the development of novel formulation (Nguyen et al. 2013; El-Menofy et al. 2014). In the present pest management scenario compared to the chemical method of pest control, the use of baculoviruses is a relatively cheap, practicable, environmental friendly, and potent tool for management of insect pests of agricultural importance of farm crops.

The present study aimed to evaluate the efficacy of nucleopolyhedrovirus (SpobNPV NBAIR1) for the management of S. obliqua on jute crop under field conditions.

\section{Materials and methods}

\section{Maintenance of host insect}

Mulberry leaves kept in plastic containers with nylon mesh served as feed for field-collected 1st instar larvae of S. obliqua. The larvae were reared till the adult stage. The eggs laid by the moths were used for maintaining a culture of tested insect to carry out the laboratory experiments. Further, the identity of the pest was confirmed through amplification of cytochrome oxidase I gene (COI) marker (Gupta et al. 2016). The nucleotide sequence was submitted to NCBI GenBank data base (accession number MK531549).

\section{Isolation and mass production of virus}

Diseased larvae of S. obliqua, hanging on top branches of jute plants with characteristic viral infection symptoms (Fig. 1), were collected during an epizootic in October 2016 at the research farm of ICAR-Central Research Institute for Jute and Allied Fibers Research, Barrackpore, West Bengal $\left(22.75^{\circ} \mathrm{N}, 88.42^{\circ}\right)$, India. The diseased larvae were brought to ICAR-NBAIR, Bangalore, and were homogenized by distilled water for $3 \mathrm{~min}$, and the crude homogenate was filtered twice by musclin and then the larval debris were removed. The filtrate was spun for $1 \mathrm{~min}$ at $500 \mathrm{rpm}$ to remove large particles. The supernatant was re-suspended for $20 \mathrm{~min}$ at 5000 rpm and the pellet was collected. Sterile distilled water $(100 \mathrm{ml})$ was used to re-suspend the pellet. The number of occlusion bodies (OBs) in the stock suspension was determined and attained to $3.2 \times 10^{4} \mathrm{OBs} / \mathrm{ml}$ using a Neubauer hemocytometer.

In vivo mass production of SpobNPV NBAIR1 was carried out on the 5th instar larvae of S. obliqua using plastic trays. About 150 5th instar larvae of S. obliqua were reared on the castor leaves. Castor leaves were washed thoroughly by distilled water, air dried, and smeared with SpobNPV NBAIR1 at $3.2 \times 10^{4} \mathrm{OBs} / \mathrm{ml}$ using the polished blunt end of a glass rod. Bouquets of these virus-contaminated leaves were placed in plastic trays with a size of $4 \mathrm{~cm} \mathrm{H} \times 40 \mathrm{~cm} \mathrm{~L} \times 30 \mathrm{~cm} \mathrm{~B}$. Fifth instar larvae of S. obliqua were allowed to feed on these leaves. Once the treated leaves were fully consumed by the larvae, fresh castor leaves were provided. All the dead, virosed larvae were collected and processed after 6-8 days of inoculation. The OBs were quantified by phase-contrast microscopy using a double ruledimproved Neubauer hemocytometer, and the virus suspension was standardized and stored in the refrigerator.

\section{Mortality bioassays}

An improved Neubauer hemocytometer was used to estimate the number of occlusion bodies (OBs) in the SpobNPV viral preparation. From the primary stock $(5 \times$ $\left.10^{4} \mathrm{OBs} / \mathrm{ml}\right), 5$ appropriate concentrations were prepared in $0.05 \%$ Triton X-100. The surface-sterilized castor leaf discs (5 mm dia) were dipped for 5-10 s in the respective viral dilutions and then air dried vertically. The treated leaf disks were placed in Petri dishes. The final concentration of OBs were estimated at 39.2, 7.8, $1.57,0.31$, and $0.06 \mathrm{OBs} / \mathrm{mm}^{2}$ leaf surface area. Five larvae were released per leaf disc, and 6 replications were maintained for each concentration. The virulence of SpobNPV was tested against early larval instars in independent experiments. Mortality rate was counted 6 days post treatment. The assay was repeated thrice on alternate days. The pooled larval mortality data was subjected to probit analysis using the software POLO (Leora 1994), and the lethal concentration to kill $50 \%$ of the test larvae $\left(\mathrm{LC}_{50}\right)$ was calculated for each larval instar. 


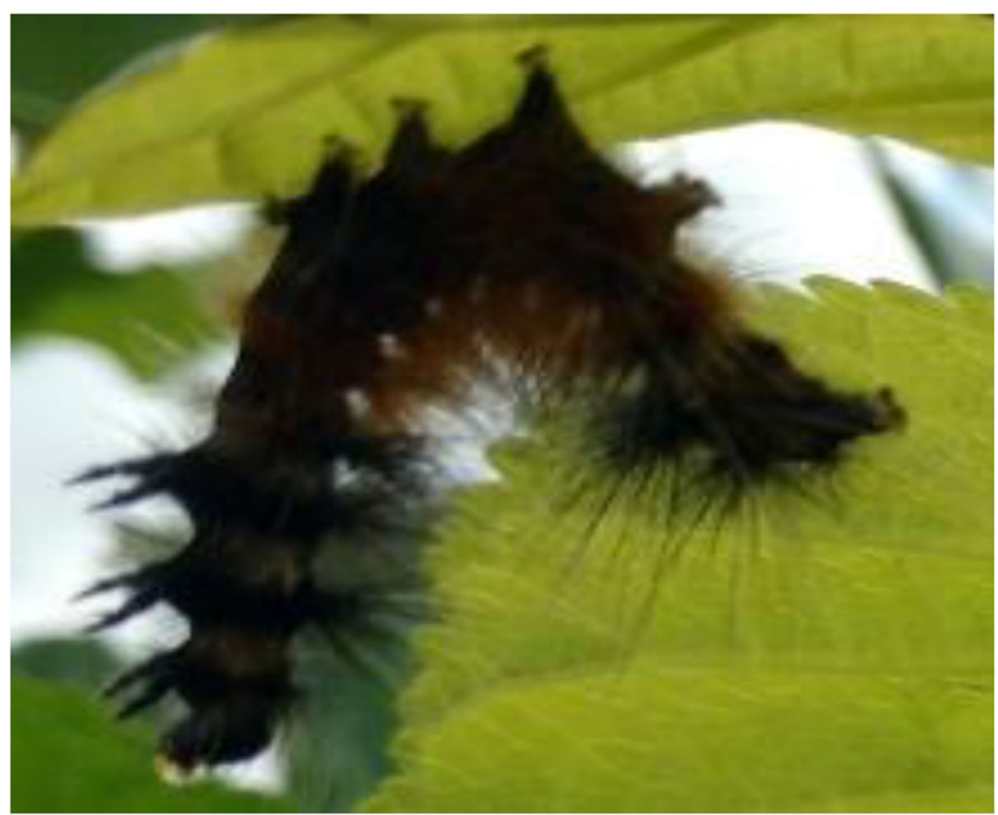

Fig. 1 Spilosoma obliqua larva showing characteristic signs of NPV infection

\section{Morphological characterization of SpobNPV}

Extracted occlusion bodies (OBs) were characterized morphologically by the use of transmission (TECNAI $120 \mathrm{kV}$ TEM (FEI, Netherlands) and scanning (SEM Quanta 250, FEI, Netherlands) electron microscopes. Before visualization, the OBs were processed with fixatives. For primary fixation, suspensions of the occlusion bodies were fixed overnight at $4{ }^{\circ} \mathrm{C}$ in vials by using glutaraldehyde $2.5 \%(\mathrm{v} / \mathrm{v})$ and paraformaldehyde $2 \%$ in phosphate buffer $(0.1 \mathrm{M}, \mathrm{pH} 7.4)$. Then the OBs were washed three times using phosphate buffer $0.1 \mathrm{M}(\mathrm{pH} 7.4)$ at $4{ }^{\circ} \mathrm{C}$ with a 30 min gap for each wash. Post fixation was carried out for $1 \mathrm{~h}$ in aqueous osmium tetroxide $\left(\mathrm{OsO}_{4}\right) 2 \%(\mathrm{v} / \mathrm{v})$ prepared in $0.1 \mathrm{M}$ phosphate buffer ( $\mathrm{pH} 7.4)$; washing was done as described for primary fixation. The samples were then dehydrated using ethanol as per Martins et al. (2005) at room temperature with graded ascending series. Critical drying point was achieved by employing dry acetone. Dried samples were placed in stubs and sputter-coated with gold for $20 \mathrm{~s}$ in an automated sputter coater (Model: EMITEC - SC 7620). The structure of OBs was viewed in a scanning electron microscope (Quanta 250, FEI, Netherlands) at 3.5 spot size $(10 \mathrm{kV}$ and $60 \mathrm{~Pa})$ and captured at $\times 25$, 000 magnification and analyzed for actual sizes/ shapes of the OBs.

For transmission electron microscope analysis of OBs, the primary fixation of pelleted OBs was done for $24 \mathrm{~h}$ at $4{ }^{\circ} \mathrm{C}$ in phosphate buffer $(0.05 \mathrm{M} ; \mathrm{pH} 7.2)$ containing $2.5 \%(\mathrm{v} / \mathrm{v})$ glutaraldehyde. Post fixing was done for $2 \mathrm{~h}$ in the same buffer containing $0.5 \%(\mathrm{v} / \mathrm{v})$ aqueous osmium tetroxide. Washing was done as described under SEM. Dehydrated samples were obtained by using a series of ascending graded alcohol. Three hundred mesh carboncoated copper grids were used to mount the dehydrated samples. The grids were first stained with uranyl acetate (saturated in water) followed by lead citrate. The grids were observed in a TECNAI $120 \mathrm{kV}$ TEM (FEI, Netherlands). The OBs and nucleocapsids were analyzed morphologically from the magnified electron micrograph by the use of a precision ruler. The shapes and sizes of OBs were determined accordingly.

\section{Molecular characterization of SpobNPV}

Purified occlusion bodies (OBs) were obtained by first centrifuging for $1 \mathrm{~min}$ at $2500 \mathrm{rpm}$. The pellet was discarded and supernatant retained as it contained the virus. The supernatant was centrifuged again to allow the OBs to settle on the side walls of centrifuge vial, the OBs thus obtained was dispersed in double-distilled water and kept at $-20^{\circ} \mathrm{C}$. For DNA extraction the purified OBs suspension was treated with 1\% SDS and proteinase $\mathrm{K}$ at $20 \mathrm{mg} / \mathrm{ml}$ followed by phenol: chloroform: isoamylalcohol (1:1:1), extraction and DNA was precipitated with ethanol. DNA was re-suspended in TE buffer and extracted DNA was visualized in $0.9 \%$ agarose gel. Based on SpobNPV sequences submitted to GenBank, primers were designed for the amplification of species-specific polh gene and the primer sequence consisted of forward primer 5'-ATGCCA GACTTCTCGTACCG-3' and reverse primer $5^{\prime}$ - 

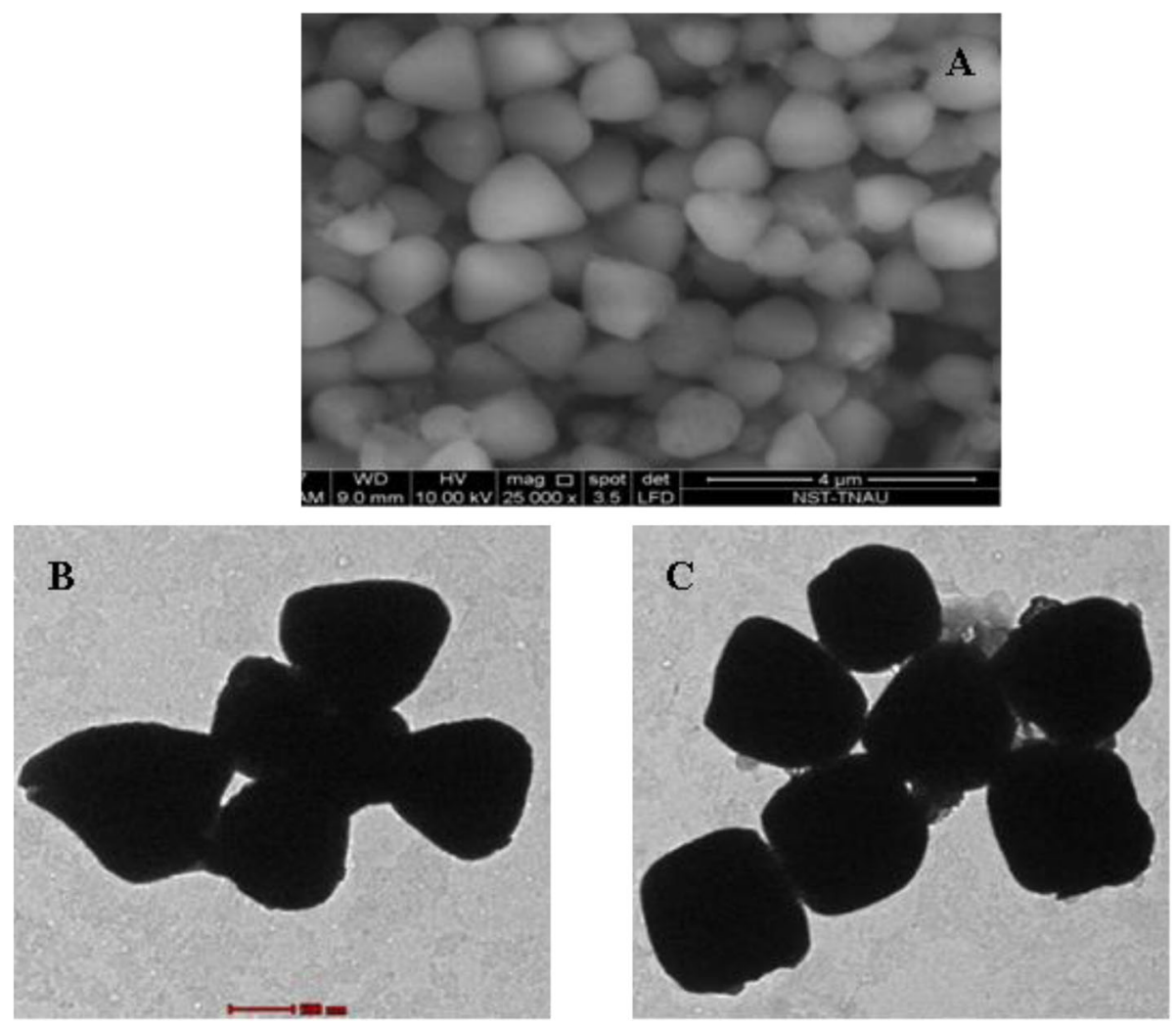

Fig. 2 Occlusion bodies (OBs) of SpobNPV. a Scanning electron micrograph of tetrahedral and triangular polyhedral OBs. b Transmission electron micrograph of triangular OBs. c Transmission electron micrograph of tetrahedral OBs

TAATACGCGGGACCGGTGAAT-3'. The PCR reaction mixture $(50 \mu \mathrm{L})$ consisted $50 \mathrm{ng}$ of template DNA, $0.25 \mathrm{U}$ of Taq DNA polymerase, $10 \mathrm{X}$ Taq buffer, $2.5 \mathrm{mM} \mathrm{MgCl} 2,2.5 \mathrm{mM}$ of each of four dNTPs, and $1 \mu \mathrm{L}$ each forward and reverse primer. The reaction was carried out in a thermal cycler (Biorad, Model T100) with initial denaturation at $95^{\circ} \mathrm{C}$ for 3 min and 35 cycles at $95^{\circ} \mathrm{C}$ for $30 \mathrm{sec}, 70{ }^{\circ} \mathrm{C}$ for $1 \mathrm{~min}$, $55^{\circ} \mathrm{C}$ for $1 \mathrm{~min}$, and a final extension step at $72^{\circ} \mathrm{C}$ for $10 \mathrm{~min}$ to obtain a PCR product of $700 \mathrm{bp}$. The PCR products were sequenced and submitted to NCBI GenBank.

\section{Host range studies}

The host range of the SpobNPV NBAIR1 was studied on a 1 day old 3rd larvae of S. litura, S. exigua, S. frugiperda, Helicoverpa armigera, Plutella xylostella, Amsacta albistriga, Maruca vitrata, Trichoplusia ni, Pieris brassicae, Agrotis ipsilon, and Bombyx mori with SpobNPV NBAIR1 at $3.2 \times 10^{4} \mathrm{OBs} / \mathrm{ml}$ concentration. The bioassays were scored 6 days post treatment to access the viral infection. All the dead larvae in the course of the assays were examined for the presence of virus OBs by smearing the larval body fluid on a glass slide, stained with
Giemsa stain, and examined using a phase-contrast light microscope under oil immersion.

\section{Field testing of SpobNPV NBAIR1}

Two field experiments were conducted at ICAR-Central Research Institute for Jute and Allied Fibers Research farm, Barrackpore, Kolkata, India, during the years 2017 and 2018, on jute to evaluate the efficacy of the formulation of SpobNPV strain NBAIR1 during the peak time of S. obliqua infestation. The field experiment was laid out in a randomized block design with a plot size of $3 \times 4 \mathrm{~m}$ and with 4 replications. Field efficacy of SpobNPV was compared to Bacillus thuringiensis var. kurstaki (Btk) NCIM2514 at $2 \mathrm{ml} / \mathrm{l}\left(\right.$ Lipel $\left.^{\oplus}\right)$, Agrilife Private Limited, Hyderabad, India, and conventional insecticide profenophos 50\% EC at $2 \mathrm{ml} / \mathrm{l}$. Jute seeds (variety JRO524) were sown during mid monsoon season (mid-July) with a row-row space of $15 \mathrm{~cm}$ and plant to plant space of 30 $\mathrm{cm}$ apart after thinning. The crop was raised following the recommended agronomical practices. Pre-treatment observation was recorded at 1 day before spraying on the number of larvae from 25 randomly selected plants. Treatments were imposed to plants with knapsack sprayer when early instar larvae were noticed. SpobNPV at $1.5 \times 10^{11} \mathrm{OBs} /$ ha with jaggery $5 \%$, glycerol $10 \%$, and 


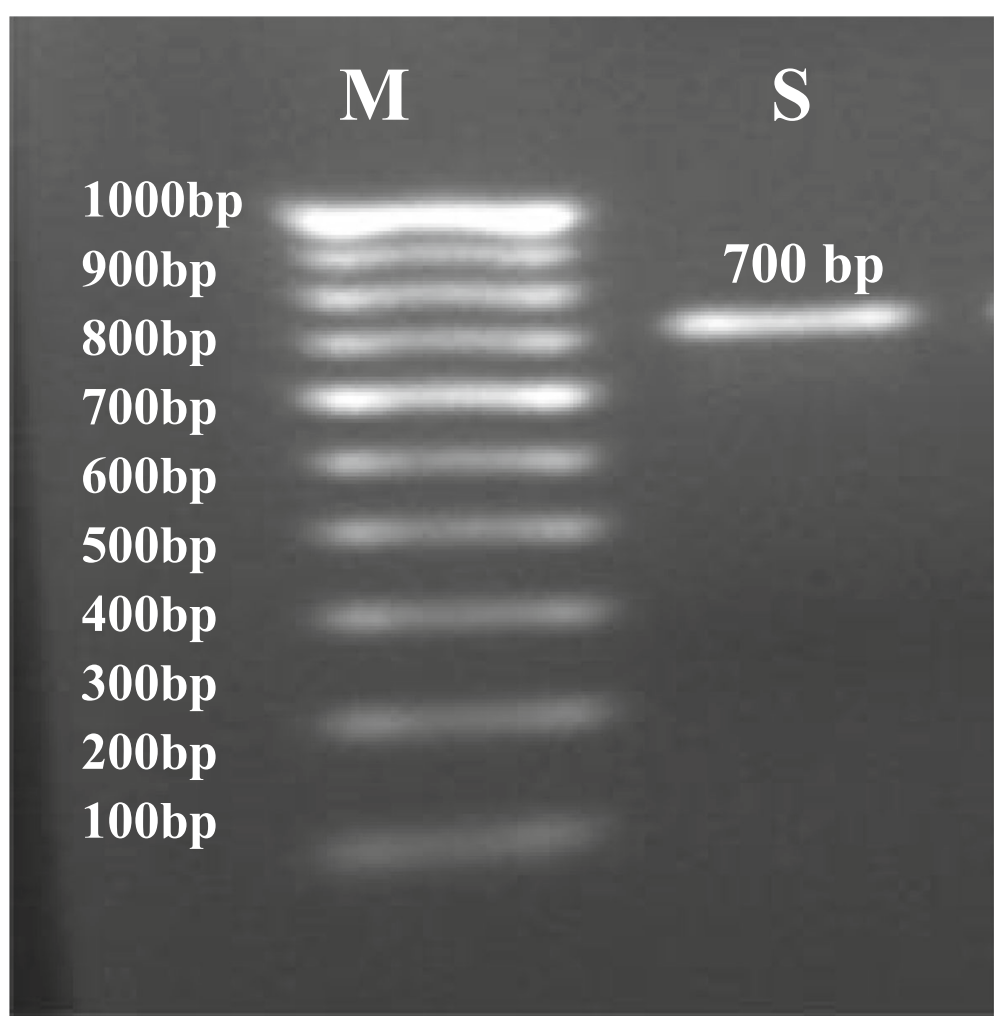

Fig. 3 PCR detection based on polh gene at 700 bp (M, Marker (M):100 bp ladder, S, Spilosoma obliqua polh NPV gene

Sandovit $0.1 \%$ was sprayed at $2 \mathrm{ml} / \mathrm{l}$ during evening hours. Btk NCIM2514 was sprayed at $2 \mathrm{ml} / \mathrm{l}$. Post treatment observations on the number of $S$. obliqua larvae were recorded at 3, 4, and 7 days after the SpobNPV application from 25 randomly selected plants.

\section{Statistical analysis}

ANOVA was used as a statistical tool for Agricultural Research (STAR, Version 2.0.1, developed by International Rice Research Institute, Manila, Philippines, 2013 to 2020. This software is used for statistical analysis.

\section{Results and discussion}

Natural epizootic of viral infection was observed in S. obliqua in jute field at Kolkata, India. Discharged body fluid was observed under a phase-contrast microscope which revealed that a large number of spherical particles resembling as baculoviral OBs. TEM studies revealed the typical baculovirus OBs of NPV with polyhedral structures. Under SEM observation, most of the OBs of S. obliqua NPV appeared as tetrahedral and triangular in shape with the size ranged from 1.04-1.72 $\mu \mathrm{m}$ with an average size of about $1.60 \mu \mathrm{m}$ (Fig. 2a). Under TEM observation, OBs appeared as triangular (Fig. 2b) and tetrahedral (Fig. 2c) in shape. The polyhedrin gene was amplified, and the amplified product was of $700 \mathrm{bp}$ (Fig. 3). The nucleotide sequence of polh and its deduced amino acid sequence were deposited to the GenBank with the accession number MK288145. Single open reading frames (ORF) that could encode polypeptides of 230 amino acids were detected. No stop codon was observed all over the amino acid sequence.

Bioassay studies showed instar dependent larval mortality pattern. The $\mathrm{LC}_{50}$ values estimated for the 1 st, 2nd, and 3rd larval instars of S. obliqua were 2.93, 5.95, and $6.73 \mathrm{OBs} / \mathrm{mm}^{2}$ respectively (Table 1 ). All the 3 early instars were equally susceptible since, there were no significant differences in $\mathrm{LC}_{50}$ values among the instars based on exclusivity of $95 \%$ confidence interval values.

Table 1 Bioassay of Spilosoma obliqua nucleopolyhedrovirus against S. obliqua

\begin{tabular}{|c|c|c|c|c|c|c|}
\hline \multirow{2}{*}{$\begin{array}{l}\text { Number } \\
\text { of larvae } \\
\text { used }\end{array}$} & \multirow{2}{*}{$\begin{array}{l}\mathrm{LC}_{50} \\
\mathrm{OBs} / \\
\mathrm{mm}^{2} \\
\text { (6th } \\
\text { day) }\end{array}$} & \multirow[t]{2}{*}{ Slope \pm SE } & \multicolumn{2}{|c|}{ Fiducial limits } & \multirow[t]{2}{*}{$x^{2}$} & \multirow[t]{2}{*}{ DF } \\
\hline & & & Lower & $\overline{\text { Upper }}$ & & \\
\hline & $1 \mathrm{st}$ in & & & & & \\
\hline \multirow[t]{2}{*}{220} & 2.93 & $0.81 \pm 0.11$ & 0.032 & 1.907 & 0.32 & 3 \\
\hline & 2nd ir & & & & & \\
\hline \multirow[t]{2}{*}{240} & 5.95 & $0.92 \pm 0.13$ & 2.283 & 11.205 & 1.20 & 3 \\
\hline & $3 \mathrm{rd}$ in & & & & & \\
\hline 300 & 6.73 & $0.96 \pm 0.11$ & 2.69 & 13.203 & 2.32 & 3 \\
\hline
\end{tabular}


Table 2 Field evaluation of SpobNPV strain NBAIR1 against Spilosoma obliqua on jute (pooled mean data for the years 2017 and 2018)

\begin{tabular}{|c|c|c|c|c|c|c|c|}
\hline \multirow[t]{2}{*}{ Particulars } & \multirow{2}{*}{$\begin{array}{l}\text { Pre- } \\
\text { treatment }\end{array}$} & \multicolumn{3}{|c|}{ Larvae/plant days after spray } & \multicolumn{3}{|c|}{ Reduction in larval population } \\
\hline & & 3 DAS & 4 DAS & $7 \mathrm{DAS}$ & 3 DAS & 4 DAS & 7 DAS \\
\hline SpobNPV $\left(1.5 \times 10^{12} \mathrm{OBs} / \mathrm{ha}\right)$ at $2 \mathrm{ml} / \mathrm{l}$ & $36.25 \pm 0.01$ & $13.10^{c} \pm 0.03$ & $9.75^{\complement} \pm 0.01$ & $1.33^{\mathrm{c}} \pm 0.00$ & $68.92^{b} \pm 0.24$ & $78.59^{b} \pm 0.01$ & $93.16^{\mathrm{b}} \pm 1.12$ \\
\hline Bacillus thuringiensis Btk at $2 \mathrm{ml} / \mathrm{l}$ & $35.50 \pm 0.03$ & $20.50^{\mathrm{b}} \pm 0.00$ & $13.25^{b} \pm 0.02$ & $3.75^{b} \pm 0.02$ & $51.36^{c} \pm 0.00$ & $70.91^{\complement} \pm 0.30$ & $80.71^{c} \pm 0.21$ \\
\hline Profenophos 50 E.C. at $2 \mathrm{ml} / \mathrm{l}$ & $37.00 \pm 0.00$ & $9.55^{d} \pm 0.01$ & $4.55^{d} \pm 0.01$ & $0.75^{d} \pm 0.01$ & $77.34^{\mathrm{a}} \pm 0.41$ & $90.01^{\mathrm{a}} \pm 0.25$ & $96.14^{\mathrm{a}} \pm 2.01$ \\
\hline Control & $38.00 \pm 0.01$ & $42.15^{\mathrm{a}} \pm 0.00$ & $45.55^{\mathrm{a}} \pm 0.02$ & $19.45^{\mathrm{a}} \pm 0.01$ & $0.00^{d} \pm 0.00$ & $0.00^{d} \pm 0.00$ & $0.00^{d} \pm 0.00$ \\
\hline SE(d) & - & 0.019 & 0.023 & 0.002 & 0.339 & 0.365 & 1.647 \\
\hline $\mathrm{CD}(P=0.05)$ & - & 0.044 & 0.051 & 0.004 & 0.739 & 0.803 & 3.628 \\
\hline
\end{tabular}

Means followed by different letters within a row indicate significant differences $(P<0.05 ;$ LSD)

The present study investigated the cross infectivity/ host range of SpobNPV on a range of insect species, viz., S. litura, S. exigua, S. frugiperda, $H$. armigera, $P$. xylostella, A. albistriga, M. vitrata, T. ni, P. brassicae, A. ipsilon, and $B$. mori. The results of the experiments revealed that SpobNPV strain NBAIR1 strain was not having cross infection against any of the above insect species tested in this study. However, cross infectivity of SpobNPV was observed in another Erebidae member commonly known as wolly bear, Olepa ricini (Sujayanand et al. 2019).

Pooled data of field experiment on the evaluation bioefficacy of SpobNPV was presented (Table 2). The efficacy of the SpobNPV was evaluated and compared to $B t k$ and profenophos treatments under field conditions on jute. Profenophos was found highly effective against S. obliqua larvae (96.14\% larval reduction) as the minimum number of larvae/plant was recorded at 3, 4, and 7 days after applications (Table 2), followed by SpobNPV and $B t$ var. kurstaki. Reduction in larval populations was recorded as 68.92, 78.59, and $93.16 \%$, respectively at 3, 4 , and 7 days after spray of SpobNPV followed by the Btk which exhibited 51.36, 70.91, and $80.71 \%$ reduction in the larval numbers, respectively at 3,4 , and 7 days after spray as compared to control (Table 2).

NPV is known for high epizootics, naturally occurring, self-perpetuating, and safe to natural enemies due to host specificity and eco-friendly. NPVs are found mostly in the order Lepidoptera (604 species), Hymenoptera (31 species), Diptera (27 species), and Coleoptera (5 species) as well as from the crustacean order Decapoda (shrimp) (Rao et al. 2015). They have enormous potential as viral biopesticides. Appreciable amount of works have been carried out across the globe on various aspects of nucleopolyhedroviruses of lepidopteran insect pests. However, with respect to the SpobNPV, only limited work has been done. SEM and TEM studies revealed that the occlusion bodies of SpobNPV are both tetrahedral and triangular with the size ranged from 1.04$1.72 \mu \mathrm{m}$. Similarly, the NPV of Euproctis chrysorrhoea appeared as crystalline structures of variable shapes and sizes ranging from 1.016 to $1.596 \mathrm{um}$. Most of the OBs of E. chrysorrhoea NPV were tetrahedral in shape and few were hexagonal in shape (Hussain et al. 2019). Senthil Kumar et al. (2015) also confirmed that NPV of S. obliqua from India was tetrahedral in shape and size ranged from 0.6 to $2.0 \mu \mathrm{m}$. But Battu et al. (1991) from India also reported that the inclusion bodies of NPV of S. obliqua were polyhedral, cubic, triangular, spherical, and oval. Tetrahedral, cuboidal, globular, and irregularshaped occlusion bodies have been described earlier for other NPVs (Smith 1976; Young and Yearian 1983; and Cheng and Carner 2000). Amplification of the highly conserved nucelopolyhedrosis virus polyhedrin gene (polh), provided a powerful tool to identify lepidopteranspecific baculoviruses (Jehle et al. 2006b; Senthil Kumar et al. 2015). It is well known that there is a high degree of genetic variation, and pathogenicity occurs in NPV isolates of the same population or from a geographically distant host population and also within a single larva. For example, 24 different genotypes of an NPV from a single larva of Panolis flammea have been identified (Harrison and Hoover 2012). The absence of cross infectivity against 11 insect species tested here indicated that SpobNPV strain NBAIR1 was highly specific and pathogenic only against the larvae of $S$. obliqua (Table 2).

Though the natural occurrence of NPV on S. obliqua has been reported as early as during 1970s (Battu et al. 1977), the studies on virulence testing under field conditions are limited. Testing the efficacy under pot culture experiments with a single application of NPV of S. obliqua at $10^{6}$ and $10^{9} \mathrm{OBs} / \mathrm{ml}$ resulted in a significant reduction of cowpea leaf damage over control (Battu and Ramakrishnan 1989). The SpobNPV strain NBAIR1 isolated in the present study was found highly effective at the lowest concentrations against the early instar larvae of S. obliqua. Hence, this strain was further field-tested on jute, which is an important host plant for S. obliqua. Field experiment results revealed that there was a significant reduction in larval populations to the tune of 68.92 , 78.59 , and $93.16 \%$, respectively at 3,4 , and 7 days post spray of SpobNPV. 


\section{Conclusion}

Management of S. obliqua by SpobNPV on the jute proved that the strain NBAIR1 could be an effective and a promising alternative to synthetic insecticides. Hence, the SpobNPV NBAIR1 could be used as an effective biocontrol agent for the management of jute hairy caterpillar S. obliqua.

\section{Abbreviations}

NBAIR: National Bureau of Agricultural Insect Resources; SpobNPV: Spilosoma obliqua nucleopolyhedrovirus; SEM: Scanning electron microscopy; TEM: Transmission electron microscopy; ICAR: Indian Agricultural Research Institute; PCR: Polymerase chain reaction; $L C_{50}$ : Lethal concentration; V/ v: Volume per volume

\section{Acknowledgements}

Thanks to ICAR-National Bureau of Agricultural Insect Resources, Bengaluru, India and ICAR-Central Research Institute for Jute and Allied Fibers, Barrackpore, Kolkata, for providing facilities to carry out this research works.

\section{Authors' contributions}

GS, MK, VRB, MM, SK, RR, TV, and CRB designed and executed the experiments and carried out the study. GS, MK, and MM wrote the manuscript. GS, MK, MM, and TV analyzed the data. All authors read and approved the final manuscript.

\section{Funding}

Not applicable

\section{Availability of data and materials}

All data generated or analyzed during this study are included in this manuscript.

\section{Ethics approval and consent to participate}

Not applicable

\section{Consent for publication}

Not applicable.

\section{Competing interests}

The authors declare that they have no competing interests.

\section{Author details}

${ }^{1}$ ICAR-National Bureau of Agricultural Insect Resources, Bengaluru 560 024, India. ${ }^{2}$ Department of Nano Science and Technology, Tamil Nadu Agricultural University, Coimbatore 641 003, India. ${ }^{3}$ ICAR-Central Research Institute for Jute and Allied Fibres, Barrackpore, Kolkata 700 120, India.

Received: 13 April 2020 Accepted: 18 June 2020

Published online: 29 June 2020

\section{References}

Battu GS, Dilawari VK, Bindea OS (1977) Investigation on microbial infections of insect pests in the Pubjab-II. Indian J Entomol 39:271-290

Battu GS, Ramakrishna N, Namprakash (1991) Size and shape of inclusion bodies of nucleopolyhedrovirus of Spilosoma obliqua. J Biol Control 5:88-92

Battu GS, Ramakrishnan N (1989) Comparative role of various mortality factors in the natural control of Spilosoma obliqua (Walker) in Northern India. J Entomol Res 13:38-42

Cheng XW, Carner GR (2000) Characterization of a new single nucleocapsid nucleopolyhedrovirus from Thysanoplusia orichalcea (Lepidoptera: Noctuidae) in Indonesia. J Invertebr Pathol 75:279-287

CPC (2004) Crop protection compendium. CAB International, Wallingford

El-Menofy W, Osman G, Assaeedi A, Salama M (2014) A novel recombinant baculovirus over expressing a Bacillus thuringiensis Cry1 AB toxin enhances insecticidal activity. Biol Proced 14:16-27

Fan X, Zheng B, Fu Y, Sun Y, Liang A (2008) Baculovirus-mediated expression of a Chinese scorpion neurotoxin improves insecticidal efficacy. Chin Sci Bull 53: $1855-1860$
Georgievska L, Joosten N, Hoover K, Cory J, Vlak J, van der Werf W (2010) Effects of single and mixed infections with wild type and genetically modified Helicoverpa armigera nucleo polyhedrovirus on movement behaviour of cotton bollworm larvae. Entomol Exp Appl 135:56-67

Gramkow A, Perecmanis S, Sousa R, Noronha E, Felix C, Nagata T, Ribeiro B (2010) Insecticidal activity of two proteases against Spodoptera frugiperda larvae infected with recombinant baculoviruses. Virol J 7:143

Gupta A, Venkatesan T, Ravi PM (2016) Morphological and molecular characterization of reared parasitoid wasps of the genus Glyptapanteles Ashmead (1904) associated with Lepidoptera in India. PLoS One 11:e0150765

Gupta G, Bhattacharya AK (2008) Assessing toxicity of post-emergence herbicides to the Spilarctia obliqua Walker (Lepidoptera: Arctiidae). J Pest Sci 81:9-15

Harrison RL, Hoover K (2012) Baculoviruses and other occluded insect viruses. In: Vega FE, Kaya HK (eds) Insect pathology. Academic Press, London, pp 73-132

Hussain B, Sivakumar G, Kannan M, War AR, Ballal CR (2019) First record of nucleopolyhedrovirus infecting brown-tail moth larvae, Euproctis chrysorrhoea (L.) (Lepidoptera: Lymantriidae) in India. Egyptian J Biol Pest Control 29:11

Jehle JA, Blissard G, Bonning B, Cory J, Herniou E, Rohrmann G, Theilmann D, Thiem S, Vlak J (2006b) On the classification and nomenclature of baculoviruses: a proposal for revision. J Virol 151(7):1257-1266

Jehle JA, Lange M, Wang H, Hu Z, Wang Y, Hauschild R (2006a) Molecular identification and phylogenetic analysis of baculoviruses from Lepidoptera. Virology 346:180-193

Jeremy A, Bryong C, Robert H (2015) Expression, delivery and function of insecticidal proteins expressed by recombinant Baculoviruses. Viruses 7:422-455

Leora Software, Polo-PC (1994) User's guide to probit or logit analysis. LeOra Software, Berkeley

Martins T, Montiel R, Medeiros J, Oliveira L, Simões N (2005) Occurrence and characterization of a nucleopolyhedrovirus from Spodoptera littoralis (Lepidoptera: Noctuidae) isolated in the Azores. J Invertebr Pathol 89:185-192

Nguyen Q, Nielsen L, Reid S (2013) Genome scale transcriptomics of baculovirusinsect interactions. Viruses 5:2721-2747

Rao GVR, Kumar CS, Sireesha K, Lava Kumar P (2015) Role of nucleopolyhedroviruses (NPVs) in the management of lepidopteran pests in Asia. In: Sree KS, Varma A (eds) Biocontrol of lepidopteran pests, Soil Biol, p 43. https://doi.org/10.1007/978-3-319-14499-32

Satpathy S, Selvaraj K, Gotyal BS, Biswas C, Gwande SP, Sarkar SK, De RK, Tripathi AN, Babu VR, Mondal K, Meena PN (2014) Problems and prospects of pest management in jute and allied fibre crops. In "International Conference on Natural Fibres (Jute and Allied Fibres), 13 to 14, August, 2014, Kolkata, pp 3036

Senthil Kumar CM, Jacob TK, Devasahayam S, D'Silva S, Jinsha J, Rajna S (2015) Occurrence and characterization of a tetrahedral nucleopolyhedrovirus from Spilarctia obliqua (Walker). J Invertebr Pathol 132:135-141

Senthil Kumar CM, Jeyaram K, Singh HB (2011) First record of the entomopathogenic fungus Entomophaga aulicae on the Bihar hairy caterpillar Spilarctia obliqua in Manipur, India. Phytoparasitica 39:67-71

Smith KM (1976) Virus-insect relationships. Longman Group Ltd, New York, p 291

Sujayanand GK, Akram M, Ashish N, Aravind K, Shripad B, Kumar SD, Raja H, Sonika P (2019) Virulence, cross infectivity and molecular characterization of Spilosoma obliqua MNPV from north India for Bihar hairy caterpillar management. Res J Biotech 14(12):58-70

Young SY, Yearian WC (1983) Pathology of a nuclear polyhedrosis virus of Rachiplusia nu in Rachiplusia ou (Lepidoptera: Noctuidae). J Invertebr Pathol 42:410-412

\section{Publisher's Note}

Springer Nature remains neutral with regard to jurisdictional claims in published maps and institutional affiliations. 